much-needed book, and is therefore sincerely welcomed. It is very well produced and I have noticed no printing errors.

A. D. Hobson

\section{TOXICOLOGY OF AROMATIC HYDROCARBONS}

Toxicology and Biochemistry of Aromatic Hydrocarbons

By Dr. Horace W. Gerarde. (Elsevier Monographs on Toxic Agents.) Pp. xiii + 329. (Amsterdam: Elsevier Publishing Co., Inc.; London: D. Van Nostrand Company, Ltd., 1960.) $30 s$.

$\mathrm{T}$ HIS useful monograph consists of two parts. Part 1 is devoted to a general treatment and includes nomenclature, sources, analysis, toxicology and biochemistry of aromatic hydrocarbons as well as a chapter on the treatment of exposure to these compounds. Part 2 deals, in handbook style, with twenty aromatic hydrocarbons of industrial importance. These include benzene, the mono-, di- and poly-alkylbenzenes, and di-, tri- and poly-cyclic aromatic hydrocarbons. Each compound is classified in a similar manner to Part 1 and given brief treatment. A chapter on solvents, fuels and lubricants, and a glossary of terminology are also included.

To the analytical toxicologist, the outstanding feature of this book is the omission of any mention of vapour-phase chromatography. On page 87 , Dr. Gerarde states that "If sufficiently sensitive methods of analysis were available, breath analysis could serve as a test for exposure to these hydro. carbons ...".

One is of the opinion that, by a combination of vapour-phase chromatography and infra-red spectrophotometry, sufficiently sensitive methods are in fact available. Perhaps, too, application of such tech. niques might eliminate the need to wait for the appearance of leucopenia or thrombocytopenia as evidence of exposure to hydrocarbons; the 'biochemical lesion' may thus be prevented from occurring. One might pertinently enlarge the discussion here and say that, in Great Britain at least, there is a great need for the establishment of a centre for research into toxicological analysis and for the provision of a routine service for the practical application of the fruits of such research. This would be one way, at least, of solving one of the problems posed in Dr. Gerarde's statement on page 87, that "The accidental ingestion of chemicals is an infrequent occurrence in industry but regrettably too common in the home".

Chapter 4 contains one or two blemishes. For example, on page 38 reference is made to ". . . benzene and its more volatile homologues ... .". This statement is ambiguous; it suggests that the homologues of benzene are more volatile than benzene itself. This, of course, is inconsistent with the statement on page 26 that ". . . progressive decrease in volatility with increasing molecular weight accompanies the lengthening of the alkyl chain".

The sentence beginning "The aromatic hydrocarbons have ...", on page 47 , should begin, "The alkyl derivatives of benzene have . ..", to make the paragraph intelligible.

It is interesting to note in Chapter 6 that the threshold limits for benzene and toluene in U.S.S.R. are lower than the American and British values; one wonders whether the Trades Unions are aware of this difference.

The binding of this soft-covered book is poor; several pages came away from my own copy after the third opening. The quality of the paper is good.

Notwithstanding these criticisms, the monograph provides a useful compilation of hitherto somewhat scattered information and it should find a place on the bookshelves of all those whose work, whether routinely or infrequently, brings them into contact with toxicology. Harold V. Street

\section{ORGANOPHOSPHORUS ANTICHOLINESTERASES}

\section{Organophosphorus Poisons :}

Anticholinesterases and Related Compounds. By D. F. Heath. (International Series of Monographs on Pure and Applied Biology. Division: Modern Trends in Physiological Sciences, Vol. 13.) Pp. vii +403 . (London and New York: Pergamon Press, 1961.) 80s. net.

7 HIS book deals with the chemistry, biochemistry and pharmacology of the organophosphorus anticholinesterases and is intended primarily for the research worker in this field. The idea is sound, for probably nowhere else is so much related information collected conveniently together into one volume. Although the book demonstrates the author's considerable experience in all three disciplines, no one person can be expected to possess all the detailod knowledge necessary to write such a book. This is borne out in the section on pharmacology in mammals where numerous errors or distortions of the accepted facts occur. Two examples suffice. Thus on p. 260 the general statement is made that complete tetanic fusion in skeletal muscles occurs at a stimulation frequency of about 25/sec., when $100 / \mathrm{sec}$. would probably be nearer the correct average for mammalian muscles. On p. 267 , the author attributes to Zaimis the conclusion that docamethonium blocks neuromuscular transmission by potentiating the action of acetylcholine. From her vast experience in this field, Prof. Zaimis has always been convinced that decamethonium acts by virtue of its own powerful depolarizing action.

For a single author to complete an up-to-date review of this length on such a complex subject he must of necessity prepare his manuscript in a hurry, and some parts of the book, particularly the refer. ences, strongly convey this impression to the reader. Fortunately, most of the errors in the references appear to consist only of misspelling of the author's names. However, one reference to work by Blaber and Creasey (p. 186) contains four errors: in the initials of one of the authors, in the year of publica. tion, in the page number of the article and in the species of animal used.

The author is a well-known research worker in the fields of chemistry and biochemistry and the sections of the book concerning these aspects of the subject are written with authority; they contain a wealth of information and should be extremely useful to those starting research in this field. Howevor, the section on pharmacology in mammals is not to be recommended, especially for those inexperienced $\begin{array}{ll}\text { in pharmacology. } & \text { W. C. BowmaN }\end{array}$ 